\title{
Ureter Visualization on Tc-99m DMSA Scintigraphy in Pediatric Patients
}

\author{
Kara $\mathrm{AO}^{1}$, Koç $\mathrm{ZP}^{2^{*}}$, Kara $\mathrm{PO}^{2}$ and Gurgoze $\mathbf{M K}^{1}$
}

${ }^{1}$ Department of Pediatric Nephrology, Fırat University, Turkey

${ }^{2}$ Department of Nuclear Medicine, Mersin University, Turkey

*Corresponding author: Zehra Pınar Koç, MD, Associate Professor, Department of Nuclear Medicine, Mersin University, 33343, Mersin, Turkey, Tel: +903242410000; E-mail: zehrapinarkoc@gmail.com

Received date: May 24, 2017; Accepted date: June 21, 2017; Published date: June 22, 2017

Copyright: () 2017 Kara AO, et al. This is an open-access article distributed under the terms of the Creative Commons Attribution License, which permits unrestricted use, distribution, and reproduction in any medium, provided the original author and source are credited.

\begin{abstract}
Purpose: The aim of this study is to investigate possible reasons of ureter visualization on Tc-99m DMSA scintigraphy.

Methods: The planar static renal scintigraphies of pediatric patients $(n=2290)$ who attended for any reason between January 2009 and May 2015 were analyzed retrospectively by the same nuclear medicine physician. In our analysis 15 patients (12 Male (M), 3 Female (F); 0-12, mean: $4 \pm 3$, 8 years old) were included in the study due to bilateral or unilateral ureter visualization on Tc-99m DMSA scintigraphy.

Results: In the visual assessment of scintigraphies, there were 7 patients with bilateral visualization and 8 patients (right in 4 patients, left in 4 patients) with unilateral. Additionally increased background activity was observed in two patients. Cortical defects and/or atrophy of kidneys were observed in $10(66 \%)$ of the patients. The background pathology in these patients were posterior urethral valve $(n=3)$, neurogenic bladder due to meningomyelocele $(n=4)$, vesicoureteral reflux $(n=3)$, urethral atresia $(n=2)$, ureterovesical obstruction $(n=1)$ and unknown $(n=2)$.
\end{abstract}

Conclusion: Ureter visualization on Tc-99m DMSA imaging usually accompanies severe kidney damage and ureteral or bladder pathology. Additionally this finding may point out the patients who could not be corrected completely by the surgical way but this issue has to be evaluated by future studies.

Keywords: DMSA; Ureter; Vesicoureteral reflux; Posterior ureteral valve

\section{Introduction}

Static renal follow imagings by means of Tc-99m DMSA scintigraphy is indicated in the acute and follow-up phases of the patients with urinary tract infection (UTI). DMSA scintigraphy shows the renal damage as functionality loss and/or renal scars of the kidney. Additionally scintigraphy may provide important prognostic information in patients with UTI. Accompanying findings to a static renal scintigraphy might be increased background activity which refers to end stage renal disease and second finding is visualization of the ureter which is usually recognized to be related with the high grade vesicoureteral reflux (VUR). According to a previous recent study acute DMSA scan in the young children with a first febrile UTI predicts dilating VUR [1]. However, in that study and other previous studies the decision was based on presence of scar in renal parenchyma. Several other studies have pointed out the same finding and have concluded that cystourethrography is indicated in only patients with DMSA abnormalities [2]. This methodology has high sensitivity and negative predictive value in the detection of high grade VUR ( $86 \%$ and $93 \%$ respectively) $[2,3]$. The Visualization of the dilated collecting system in DMSA scintigraphy has never been analyzed previously. In a previous case report this finding was observed in a patient with neurogenic bladder as a reflection of megaureter [4]. We investigated firstly in the literature in a series how ureter visualization in static renal scintigraphy may be interpreted.

\section{Materials and Method}

In our retrospective analysis 2290 DMSA scintigraphy images of the patients who attended to our department between 2009 and 2015 were re-evaluated by an experienced Nuclear Medicine physician. Fifteen patients (12 M, $3 \mathrm{~F}$; 0-12, mean: $4 \pm 3,8$ years old) with ureter visualization were included in the study. The scintigraphy findings, previous operations and diseases of the patients were recorded and follow-up results (mean $28 \pm 22$ month) of the patients were obtained (by ultrasonography, voiding or MR).

\section{Scintigraphy}

The DMSA scintigraphy was performed by the injection of approximately 1-3 $\mathrm{mCi}$ (according to the body weight) of Tc-99m DMSA by an intravenous line. After approximately 2-4 hour waiting period after injection the images were obtained in planar way in anteroposterior, bilateral lateral and oblique projections including abdomen and pelvis region by double head SPECT gamma camera equipped with low energy high resolution collimator (infinia 2, GE, Israel). 
Citation: Kara AO, Koç ZP, Gurgoze MK (2017) Ureter Visualization on Tc-99m DMSA Scintigraphy in Pediatric Patients. J Kidney 3: 142. doi:

Page 2 of 4

\section{Patients}

All the patients who were included in the study were referred for DMSA scintigraphy for identification of upper urinary tract infection and pediatric patients. Patient characteristics are summarized in Table 1 .

\begin{tabular}{|l|l|}
\hline Characteristic & Value \\
\hline Age & $4 \pm 3,8$ years old \\
\hline Gender & $12 \mathrm{M} / 3 \mathrm{~F}$ \\
\hline Operation & $13 / 15$ \\
\hline Accompanying Disease & $\begin{array}{l}\text { 1). Meningomyelocele }(n=3) \text { 2). Neurogenic Bladder }(n=4) \text { 3). Posterior Urethral } \\
\text { Valve }(n=3) \text { 4). Urethral Atresia }(n=2)\end{array}$ \\
\hline Presence of Vesicoureteral reflux & $6 / 15$ \\
\hline
\end{tabular}

Table 1: Patient characteristics.

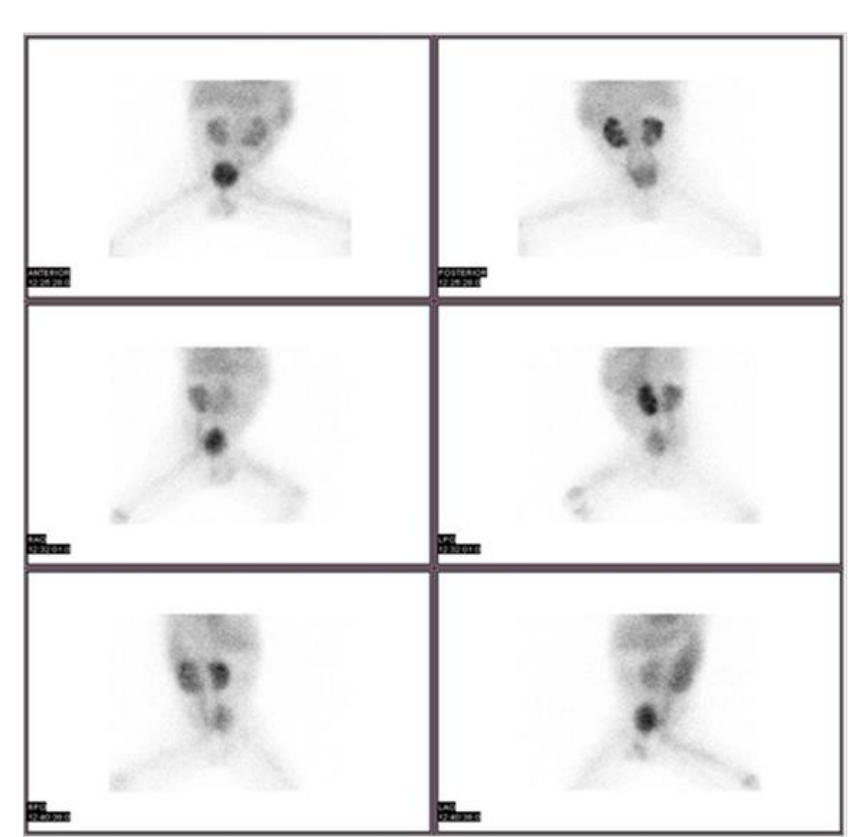

Figure 1: Two year old male patient with bilateral ureter activity and accompanying increased background activity and multiple cortical defects corresponding to end stage renal disease. The patient additionally underwent operation for meningomyelocele and hydrocephalus which has neurogenic bladder with persistence of right grade 2 vesicoureteral reflux on follow-up voiding.

\section{Results}

In the analysis of DMSA results the ureter activity was observed bilateral $(n=7)$ or unilateral (right $n=4$, left $n=4$ ). Additionally increased background activity was observed in two patients. Multiple parenchymal defects were observed in 7 patients and decreased uptake in three patients. Thus kidney functionality loss was present in total of $10 / 15(66 \%)$ of the patients (Figure 1).

Two out of 15 patients were out of follow-up and in the $28 \pm 22$ month follow-up of 13 patients; only four patients had complete improvement; in patients all of which underwent previous VUR surgery and had no other disease. The patients who had persistent disease mostly (7/9) had accompanying other diseases; especially neurogenic bladder (4/9). There were only two patients who do not have an underlying pathology as an explanation for the ureter visualization and these patients were out of follow-up (Figure 2).

\section{Discussion}

According to the previous studies approximately $2 \%$ of patients experience UTI in their first year of life and approximately $30-40 \%$ of them has associated VUR [5,6]. In the diagnosis of VUR the most important modality is voiding cystoureterogram however, this is an invasive method with high radiation dose. Direct radionuclide cystography is a sensitive method and has lower radiation dose compared to voiding [7] however,, do not provide anatomical detail thus not preferred as first imaging method in the male patients at the first diagnosis. In a recent comparative study the direct radionuclide methods has been found to be more correlated with DMSA findings and clinical results [8].

\begin{tabular}{|l|l|l|l|l|}
\hline Results & Bilateral Ureter & Unilateral Ureter & Bilateral Defect & Unilateral Defect \\
\hline Ratio & $7 / 15$ & $8 / 15$ & $7 / 15$ & $3 / 15$ \\
\hline
\end{tabular}

Table 2: Scintigraphy results.

The DMSA scan findings of the patients are summarized in Table 2.

Recent studies have indicated another potential benefit of DMSA scan to pick patients who need further imaging by voiding for diagnosis of VUR $[2,3]$. None of the patients with normal DMSA scintigraphy had high grade VUR according to these reports. The discrimination of the high and low grade (grade 1,2) reflux is 
important since high grade reflux generally need surgical correction [9].

There are three methods for correction of the VUR; first one is the medical treatment which is more preferred method in recent years secondly interventions like ureteral injection [10] and surgical correction. Ureteroneocystostomy operations has high rate of improvement (92\%) [11]. However, this is not the case in case of presence of lower urinary tract pathology.

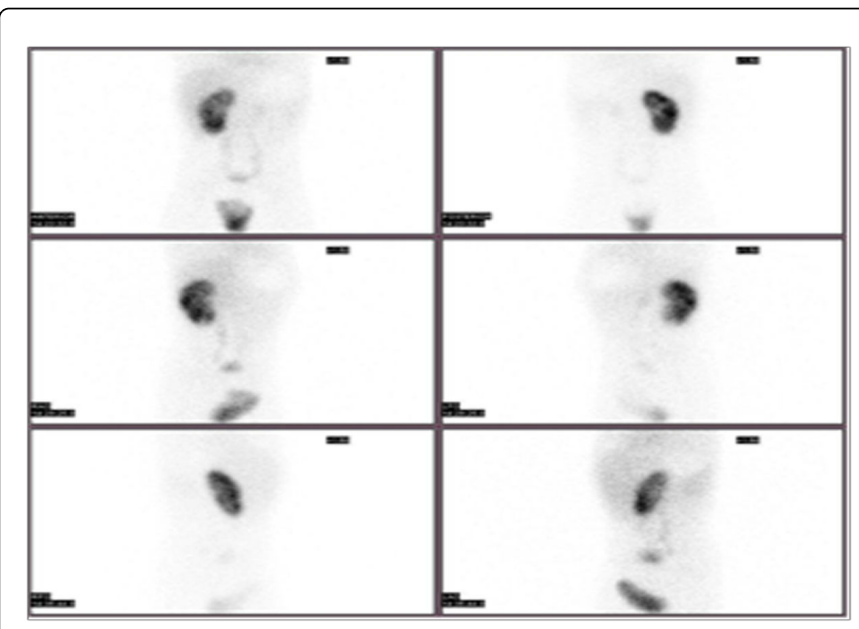

Figure 2: Four years old male patient with less functioning left kidney and right ureter activity. The patient had a normal voiding result thus he was out of follow up.

In our study we observed that the results of previous surgery may not be promising in the patients with additional pathologies other than VUR. We additionally concluded that ureter activity might indicate patients with uncorrected and severe VUR. This finding has to be analyzed carefully and might contribute to our routine practice. Although in this study we investigated the positive finding, the importance of negativity of this finding has to be evaluated in future studies.

Leonardo et al. have conducted a study in patients with lower urinary tract dysfunction (LUTD); they have observed that in these kind of patients renal scarring may be a result of poor drainage of the collecting system, associated VUR or recurrent previous UTI's as it was previously published $[12,13]$. Similarly in our group of patients the ratio of functionality loss in kidneys was high since most of our patients had LUTD. It has been previously reported that LUTD is associated with recurrent UTI's [14,15]. Although VUR even in high grades do not cause UTI's alone [16] infravesical obstruction is another cause of the UTI. Additionally the VUR is the most common cause of the UTI in the patients with LUTD [17]. Similarly another group of researchers have investigated the patients with spina bifida and have observed that in case of association with VUR and febrile UTI these patients has risk of having renal scars [18]. The patients in this study had two risk factors for UTI, both LUTD and VUR. We also observed that in case of presence of only VUR the pathology might be corrected by surgery. The patients with VUR who were reviewed in the long term follow-up with DMSA scintigraphy by Sukamoto et al. and had both new renal scars and functional loss (decrease in RU\% more than 20\%) were in all the children with neurogenic bladder [19]. In this study none of the patients with neurogenic bladder benefitted from antireflux surgery.

In a previous study it has been suggested to correct the primary pathology before correcting the VUR in these kinds of patients with neurogenic bladder [20]. There are effective surgical treatment alternatives for the neurogenic bladder [21]. However, another study has indicated that these patients with the neurogenic bladder may be conservatively followed-up in case of reaching five or six years old eventless disease course [22]. It has been reported that the scintigraphy is a good follow-up method in the patients with neurogenic bladder secondary to the meningomyelocelee [23]. If the follow-up considered necessary for scintigraphic follow-up might be suggested in the patients with neurogenic bladder. Since these patients are more prone to high grade VUR and recurrent UTI thus renal damage.

The study limitations are retrospective nature of the study with limited follow-up of two patients with negative results who were out of follow up. This study was based on a positive finding and lacks investigation of negative finding. The patient group consisted of a heterogeneous group of patients with different pathologies. This study might be repeated in the more selected patient groups like only patients with neurogenic bladder.

The analysis of the ureter activity in the DMSA scintigraphy pointed out the patients with previous uncorrected VUR surgery mostly in the patients with lower urinary tract pathologies. This finding may contribute as a selecting tool in patients with lower urinary tract pathologies and VUR but this has to be evaluated by future prospective studies.

\section{Conflict of Interest Statement}

The authors declare no conflict of interest.

\section{References}

1. Sheu JN, Wu KH, Chen SM, Tsai JD, Chao YH, et al. (2013) Acute 99mTc DMSA scan predicts dilating vesicoureteral reflux in young children with a first febrile urinary tract infection: a population-based cohort study. Clin Nucl Med 38: 163-168.

2. Shih BF, Tsai JD, Tsao CH, Huang FY (2014) Reappraisal of the effectiveness of $99 \mathrm{mTc}$-dimercaptosuccinic acid scans for selective voiding cystourethrography in children with a first febrile urinary tract infection. Kaohsiung J Med Sci 30: 608-612.

3. Fuente MÁ, Costa TS, García BS, Serrano MA, Alonso MS, et al. (2014) Practical approach to screen vesicoureteral reflux after a first urinary tract infection. Indian J Urol 30: 383-386.

4. Türkölmez S, Ors D, Korkmaz M (2005) Megaureter visualization on Tc-99m DMSA scintigraphy. Ann Nucl Med 19: 421-423.

5. Mårild S, Jodal U (1998) Incidence rate of first-time symptomatic urinary tract infection in children under 6 years of age. Acta Paediatr 87: 549-552.

6. Jacobson SH, Hansson S, Jakobsson B (1999) Vesico-ureteric reflux: Occurrence and long-term risks. Acta Paediatr Suppl 88: 22-30.

7. Sükan A, Bayazit AK, Kibar M, Noyan A, Soyupak S, et al. (2003) Comparison of direct radionuclide cystography and voiding direct cystography in the detection of vesicoureteral reflux. Ann Nucl Med 17: 549-553.

8. Dalirani R, Mahyar A, Sharifian M, Mohkam M, Esfandiar N, et al. (2014) The value of direct radionuclide cystography in the detection of vesicoureteral reflux in children with normal voiding cystourethrography. Pediatr Nephrol 29: 2341-2345.

9. Montini G, Hewitt I (2009) Urinary tract infections: To prophylaxis or not to prophylaxis? Pediatr Nephrol 24: 1605-1609. 
Citation: Kara AO, Koç ZP, Gurgoze MK (2017) Ureter Visualization on Tc-99m DMSA Scintigraphy in Pediatric Patients. J Kidney 3: 142. doi:

Page 4 of 4

10. Corbetta JP, Bortagaray JI, Weller S, Ruiz J, Burek C, et al. (2015) The use of polyacrylate-polyalcohol copolymer hydrogel in the endoscopic treatment of primary vesicoureteral reflux in children. J Pediatr Surg 50: 485-488.

11. Dogan HS, Bozaci AC, Ozdemir B, Tonyali S, Tekgul S (2014) Ureteroneocystostomy in primary vesicoureteral reflux: Critical retrospective analysis of factors affecting the postoperative urinary tract infection rates. Int Braz J Urol 40: 539-545.

12. Leonardo CR, Filgueiras MF, Vasconcelos MM, Vasconcelos R, Marino VP, et al. (2007) Risk factors for renal scarring in children and adolescents with lower urinary tract dysfunction. Pediatr Nephrol 22: 1891-1896.

13. Ottolini MC, Shaer CM, Rushton HG, Majd M, Gonzales EC, et. al (1995) Relationship of asymptomatic bacteriuria and renal scarring in children with neuropathic bladders who are practicing clean intermittent catheterization. J Pediatr 127: 368-372.

14. Naseer SR, Steinhardt GF (1997) New renal scars in children with urinary tract infections, vesicoureteral reflux and voiding dysfunction: A prospective evaluation. J Urol 158: 566-568.

15. Snodgrass W (1991) Relationship of voiding dysfunction to urinary tract infection and vesicoureteral reflux in children. Urology 38: 341-344.

16. Holland NH, Jackson EC, Kazee M, Conrad GR, Ryo UY (1990) Relation of urinary tract infection and vesicoureteral reflux to scars: Follow-up of thirty-eight patients. J Pediatr 116: S65-71.
17. Teichman JM, Scherz HC, Kim KD, Cho DH, Packer MG, et al. (1994) An alternative approach to myelodysplasia management: Aggressive observation and prompt intervention. J Urol 152: 807-811.

18. Shiroyanagi Y, Suzuki M, Matsuno D, Yamazaki Y (2009) The significance of 99 mtechnetium dimercapto-succinic acid renal scan in children with spina bifida during long-term follow-up. J Urol 181: 2262-2266.

19. Sukamoto E, Itoh K, Morita K, Katoh C, Nakada K, et al. (1999) Reappraisal of Tc-99m DMSA scintigraphy for follow-up in children with vesicoureteral reflux. Ann Nucl Med 13: 401-406.

20. Onishi N, Uchida A, Kiwamoto H, Esa A, Sugiyamka T, et al. (1991) [Management of vesicoureteral reflux in patients with neurogenic bladder dysfunction]. Japanese J Urology. 82: 473-480.

21. Hayashi Y, Yamataka A, Kaneyama K, Kato Y, Lane GJ, et al. (2006) Review of 86 patients with myelodysplasia and neurogenic bladder who underwent sigmoidocolocystoplasty and were followed more than 10 years. J Urol 176: 1806-1809.

22. Pompino HJ, Devens K, Kübler U, Morales W (1976) Long-term results of obstructive neurogenic bladder in children with myelomeningocele. Dev Med Child Neurol Suppl 37: 89-93.

23. Thomsen F, Thorup J, Johnsen A (1986) Hippuran renography and scintigraphy in children with myelomeningocele. Eur Urol 12: 12-15. 